\title{
Pulmonary vascular resistance in children with congenital heart disease
}

\author{
NJH DAVIES, EA SHINEBOURNE, MJ SCALLAN, TA SOPWITH, DM DENISON \\ From the Lung Function Unit and Paediatric Cardiology Department, Brompton Hospital, London
}

\begin{abstract}
Pulmonary and systemic blood flow and pulmonary vascular resistance were measured in 21 children with congenital heart disease. Blood flow was calculated by the direct Fick method, using measurements of metabolic gas exchange obtained by remote respiratory mass spectrometry. The observations showed that the administration of oxygen caused an appreciable fall in pulmonary vascular resistance in 16 of the 21 children studied and that this fall would not have been appreciated from a study of pulmonary arterial pressure alone as it was masked by a corresponding rise in blood flow. In 10 of 14 children, in whom superior vena caval blood was also sampled, the rise in flow was largely due to an increase in intracardiac left to right shunt. It was accompanied by widening of the alveolar-arterial oxygen gradient, perhaps due to imperfect gas equilibration within the lung.
\end{abstract}

Pulmonary vascular resistance is conventionally calculated as the mean pressure drop across the lungs' vascular bed divided by the flow (per square metre of body surface) passing through it.' Pulmonary vascular disease is inferred from the presence of an irreversibly raised resistance, reversibility being assessed by the response of the vascular bed to oxygen or to other vasodilator agents such as tolazoline. ${ }^{2}$

Use of the direct Fick principle to measure pulmonary blood flow, on which the assessment of reversibility depends, requires sampling of pulmonary arterial and pulmonary venous blood as well as measurements of metabolic gas exchange. Elegant techniques have been developed for the determination of oxygen consumption in air, ${ }^{3}$ but simple, rapid, and accurate estimation of gas exchange while the patient breathes $100 \%$ oxygen has proved more difficult to achieve. Remote mass spectrometry simplifies this problem because it permits continuous monitoring of end tidal and mixed expired gas tensions, which in turn permits the easy recognition of respiratory steady states.

\section{Methods}

Measurements were made in 21 children referred for further study of suspected congenital heart dis-

Address for reprint requests: Professor DM Denison, Lung Function Unit, Brompton Hospital, London SW3 6HP.

Accepted 9 July 1984 ease. Table 1 gives anthropometric data and the final diagnoses made on these patients, who were between 5 months and 11 years old. They are listed in order of their pulmonary artery pressures, when breathing air, at the time of study. Intravascular pressures were measured via size 6 or 7 French NIH catheters filled with heparinised saline, connected to Bell and Howell pressure transducers (4-327L223); they were displayed on a Patient Automated Monitor (S E Laboratories, amplifer type SEM 312) with an ultraviolet chart recorder. In 14 patients left atrial (pulmonary venous) pressure was measured directly, and in seven pulmonary arterial wedge pressure was measured with a Swan-Ganz inflatable balloon catheter.

The same protocol was followed on all occasions. Children were premedicated with trimeprazine, papaveretum, and either atropine or hyoscine. They were anaesthetised with alphaxolone-alphadolone acetate (Althesin) by continuous intravenous infusion. The depth of anaesthesia was followed using a Cerebral Function Monitor (Devices). Pancuronium bromide was used for muscle relaxation. After induction the children were intubated and ventilated with a Brompton-Manley ventilator. All breathed from the same circuit (fig 1). Compressed air or oxygen was delivered to the ventilator via graduated air or oxygen flowmeters (Rotameter), which were set to give a constant minute volume throughout a study on any one child. The outflow from the ventilator led to a low volume and low resistance valve box (Hans Rudolph) modified to fit directly on to an 
Table 1 Anthropometric details, mean pulmonary artery pressure $(\overline{P A P})$, and final diagnosis in 21 children studied

\begin{tabular}{|c|c|c|c|c|c|}
\hline $\begin{array}{l}\text { Case } \\
\text { No }\end{array}$ & $\begin{array}{l}\overline{P A P} \\
(m m H g)\end{array}$ & $\begin{array}{l}\text { Age } \\
(y)\end{array}$ & $\begin{array}{l}\text { Height } \\
\text { (cm) }\end{array}$ & $\begin{array}{l}\text { Weight } \\
(\mathrm{kg})\end{array}$ & Diagnosis \\
\hline $\begin{array}{l}1 \\
2 \\
3 \\
4 \\
5 \\
6 \\
7 \\
8 \\
9\end{array}$ & $\begin{array}{l}13 \\
13 \\
15 \\
15 \\
15 \\
17 \\
18 \\
18 \\
19\end{array}$ & $\begin{array}{c}3 \\
4 \\
13 / 12 \\
5 \\
3 \\
3 \\
2 \\
3 \\
10 / 12\end{array}$ & $\begin{array}{r}103 \\
109 \\
70 \\
120 \\
98 \\
91 \\
100 \\
100 \\
71\end{array}$ & $\begin{array}{r}15.0 \\
16.5 \\
9.4 \\
21.5 \\
14.7 \\
10.5 \\
14.0 \\
14.5 \\
9.4\end{array}$ & \multirow{3}{*}{$\begin{array}{l}\text { ASD, PDA } \\
\text { ASD } \\
\text { VSD } \\
\text { ASD } \\
\text { ASD } \\
\text { ASD } \\
\text { ASD } \\
\text { HAPVD } \\
\text { VSD, } \\
\text { coarctation } \\
\text { VSD, PAB } \\
\text { VSD, PAB } \\
\text { VSD } \\
\text { VSD, PDA } \\
\text { PDA } \\
\text { ASD, VSD } \\
\text { VSD } \\
\text { APW } \\
\text { VSD } \\
\text { VSD } \\
\text { PDA, } \\
\text { coarctation } \\
\text { TGA, VSD }\end{array}$} \\
\hline $\begin{array}{l}10 \\
11 \\
12 \\
13 \\
14 \\
15 \\
16 \\
17 \\
18 \\
19 \\
20\end{array}$ & $\begin{array}{r}22 \\
23 \\
48 \\
52 \\
52 \\
56 \\
60 \\
63 \\
85 \\
120 \\
32\end{array}$ & $\begin{array}{l}2 \\
2 \\
3 \\
6 \\
3 \\
6 \\
8 \\
11 \\
8 \\
8 \\
5 / 12\end{array}$ & $\begin{array}{r}81 \\
84 \\
88 \\
108 \\
93 \\
96 \\
125 \\
134 \\
122 \\
122 \\
61\end{array}$ & $\begin{array}{r}10.0 \\
8.4 \\
12.3 \\
14.9 \\
11.4 \\
12.6 \\
22.9 \\
24.0 \\
20.0 \\
17.7 \\
5.5\end{array}$ & \\
\hline 21 & 54 & 6 & 106 & $14 \cdot 6$ & \\
\hline
\end{tabular}

ASD and VSD - atrial and ventricular septal defects; HAPVDhemianomalous pulmonary venous drainage; PDA - patent ductus arteriosus; TGA - arterial transposition; PAB - pulmonary artery band; APW-aortopulmonary window.

uncuffed endotracheal tube. These were carefully chosen to match the size of the child's trachea and to minimise gas leaks.

The return flow from the child to the ventilator passed through a mixing box (fig 1). A small and constant flow of an indicator gas, argon, was injected into the breathing circuit, immediately upstream of this box, and the composition of the mixed expirate so marked was determined continuously at the outflow of the box by remote mass spectrometry. Expired flows of individual gases (oxygen, carbon dioxide, and nitrogen) were measured from the dilution of the indicator, and oxygen consumption

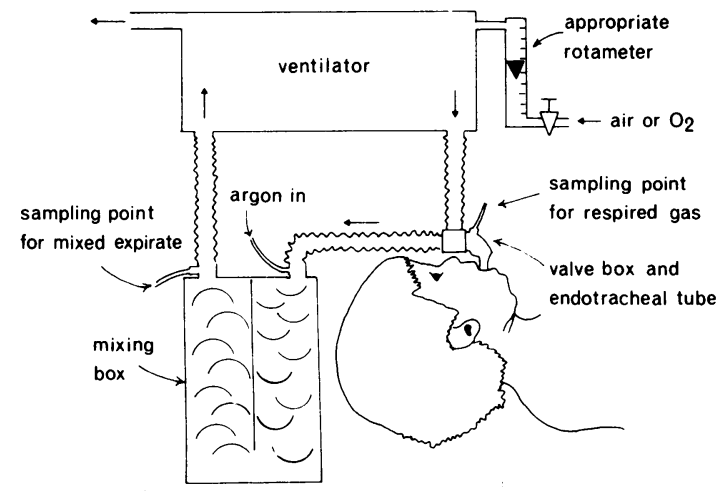

Fig 1 Diagram of the breathing circuit.
$\left(\dot{\mathrm{V}}_{2}\right)$, carbon dioxide production, $\left(\dot{\mathrm{V}} \mathrm{CO}_{2}\right)$, respiratory exchange ratio (R), and expired minute volume (VE), were calculated on an effectively continuous basis. The analyser was a quadrupole instrument (200 MGA, T C Centronic). This method of measuring respired volumes and metabolic gas exchange is known to be accurate to within $\pm 5 \%$. ${ }^{4}$

The partial pressures of nitrogen, oxygen, and carbon dioxide could also be followed continuously in gas flowing through the endotracheal tube which enabled us to determine easily whether ventilation was adequate, to decide when respiratory steady states has been achieved, and to know when alveolar nitrogen had been washed out sufficiently for measurements of the effects of oxygen to proceed. In a steady state the respiratory exchange ratio equals the respiratory quotient. Thus, if carbon dioxide production is known, oxygen consumption during a period of breathing pure oxygen can be calculated using the $R$ value measured during the previous period breathing air, as the respiratory quotient depends solely on the nature of the fuel being burnt and this is independent of the gas inspired.

At the beginning and end of each study the air or oxygen passing through the rotameter to the ventilator was led directly into the mixing box, and the extent to which it diluted the incoming argon was noted. In this way the flow of gas escaping from the child, past the uncuffed endotracheal tube, could be calculated. This leak was found to be negligible on all occasions.

In the present study argon was delivered to the breathing circuit and gas samples were drawn from the circuit through lengths of fine polythene tubing 30 metres in length. This permitted all the analytical equipment apart from the tubing to be outside the laboratory and so allowed routine cardiac catheterisation to proceed without interruption. The systematic error of measurement of metabolic gas exchange by this method is equal to or less than $0.6 \%$ and the standard deviation of single estimates is $\pm 3 \%$. $^{5}$

Once the catheters were in place and end tidal carbon dioxide tension was constant (within $2 \mathrm{~mm} \mathrm{Hg}(0.27 \mathrm{kPa})$ over several minutes), volumes of at least $5 \mathrm{ml}$ blood were withdrawn to clear the dead space. Blood samples were then withdrawn from both catheters simultaneously at the same steady rate, over one minute. During the sampling period repeated measurements of metabolic gas exchange were obtained from the composition of the marked expirate in the mixing box. After an interval of one to two minutes, to confirm that the child was still in a steady state, these blood and gas measurements were repeated. The inflow to the ventilator was then changed from air to oxygen. After an 
interval of at least 10 minutes, during which end tidal gas tensions were monitored to ensure that alveolar nitrogen pressure $\left(\mathrm{PN}_{2}\right)$ fell below $30 \mathrm{~mm} \mathrm{Hg} \mathrm{(4} \mathrm{kPa)} \mathrm{and} \mathrm{alveolar} \mathrm{carbon} \mathrm{dioxide}$ pressure $\left(\mathrm{PCO}_{2}\right)$ remained constant, duplicate sets of measurements were repeated. In 14 of the 21 children blood was also sampled from a point high in the superior vena cava while the patient was breathing air at the beginning of the study, and again when breathing oxygen at the end of the study.

The blood samples were drawn into heparinised $1 \mathrm{ml}$ plastic syringes. The syringes were checked for the absence of gas bubbles, capped, and stored in a vacuum flask filled with crushed ice until the samples were analysed on an automatic $\mathrm{pH}$ and blood gas electrode system (Corning 165) 1-20 minutes later. The apparatus was calibrated immediately before and after each set of measurements with moist gas mixtures of known composition and buffer solutions of known pH. Studies with blood tonometered with physiological concentrations of oxygen and carbon dioxide had previously shown that the system measured blood gas tensions to an accuracy of $\pm 2 \mathrm{~mm} \mathrm{Hg}(0 \cdot 27 \mathrm{kPa})$. A separate sample of each child's blood was analysed spectrophotometrically to determine its haemoglobin concentration.

The extent to which diffusion of oxygen out of those syringes containing blood with a very high oxygen pressure $\left(\mathrm{PO}_{2}\right)$ might introduce error was examined in a separate experiment. A pair of syringes was filled from the same blood sample after tonometry with $100 \%$ oxygen. One of the pair was analysed immediately, the other after storage on ice (as described above) for 20 minutes. The mean (SD) values of $\mathrm{PO}_{2}$ in 15 such comparisons were 635 (22) $\mathrm{mm} \mathrm{Hg}(84(2.9) \mathrm{kPa})$ in the aliquot analysed immediately and $581(21) \mathrm{mm} \mathrm{Hg}(77(2 \cdot 8) \mathrm{kPa})$ in the delayed sample. Tonometry with a mixture of $95 \%$ oxygen and $5 \%$ carbon dioxide had no effect on the magnitude of this drop in $\mathrm{PO}_{2}$. The importance of this fall on the calculation of blood flow is considered later.

The gas contents of systemic arterial, pulmonary arterial, and vena caval blood were calculated from their measured tensions, using the oxygen and carbon dioxide dissociaton curve data of Kelman. ${ }^{6}$ The solubility of free oxygen in blood was assumed to be $0.003 \mathrm{ml} / 100 \mathrm{ml} / \mathrm{mm} \mathrm{Hg}$. Total pulmonary and systemic blood flows were determined by combining these data with the measurements of steady state gas exchange, using the Fick principle ${ }^{7}$ and assuming that the respiratory quotient was unchanged. Pulmonary vascular resistance was calculated in the normal way-that is, by dividing the pressure gradient across the vascular bed by the total pulmonary flow (Qp).

Table 2 Oxygen uptakes $\left(\grave{V}_{2}\right)$ and blood gas measurements breathing air and breathing oxygen

\begin{tabular}{|c|c|c|c|c|c|c|c|c|}
\hline \multirow{2}{*}{$\begin{array}{l}\text { Case } \\
\text { No }\end{array}$} & \multicolumn{2}{|c|}{$\dot{\mathrm{V}} \mathrm{O}_{2}(\mathrm{ml} \mathrm{STP} / \mathrm{min})$} & \multicolumn{2}{|c|}{$\mathrm{PaO}_{2}(\mathrm{~mm} \mathrm{Hg})$} & \multicolumn{2}{|c|}{$\mathrm{PvO}_{2}(\mathrm{~mm} \mathrm{Hg})$} & \multicolumn{2}{|c|}{$\mathrm{PaCO}_{2}(\mathrm{~mm} \mathrm{Hg})$} \\
\hline & $o b s$ & pred & Air & Oxygen & Air & Oxygen & Air & Oxygen \\
\hline 1 & 57 & 113 & 114 & 491 & 53 & 133 & 39 & 35 \\
\hline 2 & 95 & 124 & 98 & 439 & 53 & 103 & 32 & 35 \\
\hline 3 & 66 & 70 & 86 & 350 & 46 & 72 & 31 & 31 \\
\hline 4 & $125^{*}$ & 150 & $123^{*}$ & 375 & $69^{*}$ & 196 & $35^{*}$ & 35 \\
\hline 5 & 70 & 108 & 93 & 403 & 52 & 178 & 35 & 37 \\
\hline 6 & 54 & 89 & 92 & 527 & 61 & 287 & 38 & 41 \\
\hline 7 & 79 & 108 & 109 & 491 & 50 & 187 & 20 & 19 \\
\hline 8 & 73 & 128 & 100 & 395 & 55 & 162 & 31 & 32 \\
\hline 9 & 57 & 72 & 74 & 362 & 45 & 67 & 44 & 46 \\
\hline 10 & 77 & 83 & 77 & 389 & 47 & 104 & 32 & 31 \\
\hline 11 & 84 & 80 & 73 & 394 & 43 & 77 & 32 & 34 \\
\hline 12 & 61 & 92 & 89 & 411 & 43 & 66 & 26 & 28 \\
\hline 13 & 71 & 126 & 85 & 385 & 56 & 185 & 33 & 35 \\
\hline 14 & 48 & 94 & 80 & 445 & 42 & 117 & 31 & 30 \\
\hline 15 & 73 & 102 & 65 & 333 & 53 & 223 & 22 & 21 \\
\hline 16 & 104 & 156 & 54 & 157 & 42 & 58 & 37 & 40 \\
\hline 17 & 96 & 143 & 112 & 406 & 38 & 46 & 33 & 33 \\
\hline 18 & 99 & 140 & 62 & 339 & 40 & 62 & 31 & 31 \\
\hline 19 & 84 & 132 & 76 & 450 & 34 & 40 & 36 & 36 \\
\hline 20 & 38 & 43 & 67 & 369 & 29 & 40 & 23 & 28 \\
\hline 21 & 63 & 118 & 54 & 304 & 43 & 62 & 60 & 39 \\
\hline
\end{tabular}

Conversion: traditional to SI units $-\mathrm{PaO}_{2}, \mathrm{PvO}_{2}$, and $\mathrm{PaCO}_{2}: 1 \mathrm{~mm} \mathrm{Hg} \approx 0.13 \mathrm{kPa}$.

STP-standard temperature and pressure;

obs-values obtained in this study;

pred-predicted values from Lee and Iliff';

$\mathrm{PaO}_{2}$ - systemic arterial oxygen tension;

$\mathrm{PvO}_{2}$ - pulmonary arterial oxygen tension;

$\mathrm{PaCO}_{2}-$ systemic arterial carbon dioxide tension.

*Measurements made breathing $41 \%$ oxygen rather than air. 
Table 3 Systemic and pulmonary arterial blood oxygen content differences $\left(C(a-v) O_{2}\right)$, blood flow, and pressure gradient measurements

\begin{tabular}{|c|c|c|c|c|c|c|}
\hline \multirow[t]{2}{*}{ Case No } & \multicolumn{2}{|c|}{$C(a-v) O_{2}(m l / 100 \mathrm{ml})$} & \multicolumn{2}{|c|}{$\dot{Q} p(l / m i n)$} & \multicolumn{2}{|c|}{$d p(m m H g)$} \\
\hline & $\boldsymbol{A i r}$ & Oxygen & Air & Oxygen & Air & Oxygen \\
\hline $\begin{array}{l}1 \\
2 \\
3 \\
4 \\
5 \\
6 \\
7 \\
8 \\
9 \\
10 \\
11 \\
12 \\
13 \\
14 \\
15 \\
16 \\
17 \\
18 \\
19 \\
20 \\
21\end{array}$ & $\begin{array}{l}2.8 \\
2.0 \\
2.8 \\
0.91^{*} \\
1.6 \\
1.1 \\
2.2 \\
1.8 \\
2.4 \\
2.1 \\
2.6 \\
2.5 \\
1.2 \\
2.4 \\
0.61 \\
5.2 \\
5.6 \\
3.6 \\
5.7 \\
0.67 \\
4.2\end{array}$ & $\begin{array}{l}1.4 \\
1.4 \\
1.8 \\
0.63 \\
0.77 \\
0.76 \\
1.0 \\
0.60 \\
2.1 \\
1.3 \\
1.6 \\
2.1 \\
0.69 \\
0.99 \\
0.43 \\
4.1 \\
4.9 \\
2.5 \\
5.6 \\
0.55 \\
2.8\end{array}$ & $\begin{array}{c}2.0 \\
4.8 \\
2.4 \\
13.8 \\
4.4 \\
5.1 \\
3.7 \\
4.1 \\
2.3 \\
3.7 \\
3.4 \\
2.4 \\
5.8 \\
2.1 \\
12.0 \\
3.6 \\
1.7 \\
2.8 \\
1.5 \\
0.58 \\
1.5\end{array}$ & $\begin{array}{c}4 \cdot 4 \\
6 \cdot 6 \\
3 \cdot 7 \\
21 \cdot 3 \\
9 \cdot 2 \\
7 \cdot 4 \\
7 \cdot 8 \\
12 \cdot 7 \\
2 \cdot 6 \\
5 \cdot 8 \\
4 \cdot 8 \\
3.0 \\
10.8 \\
5 \cdot 3 \\
17 \cdot 0 \\
4 \cdot 7 \\
2.0 \\
3.5 \\
1.5 \\
0.92 \\
2.9\end{array}$ & $\begin{array}{r}7 \\
8 \\
8 \\
9 * \\
9 \\
7 \\
10 \\
11 \\
9 \\
15 \\
16 \\
41 \\
36 \\
45 \\
52 \\
53 \\
56 \\
78 \\
110 \\
20 \\
44\end{array}$ & $\begin{array}{r}6 \\
6 \\
8 \\
9 \\
9 \\
10 \\
11 \\
11 \\
7 \\
15 \\
17 \\
41 \\
32 \\
47 \\
50 \\
65 \\
54 \\
79 \\
104 \\
21 \\
41\end{array}$ \\
\hline
\end{tabular}

Conversion: SI to traditional units-dp: $1 \mathrm{~mm} \mathrm{Hg} \approx 0.13 \mathrm{kPa}$.

Qp-total pulmonary flow;

dp-pressure gradient across the pulmonary vascular bed.

* Measurements made breathing $41 \%$ oxygen rather than air.

\section{Results}

In two of the 21 children the systemic arterial carbon dioxide tensions in air and oxygen differed by more than $4 \mathrm{~mm} \mathrm{Hg}(0.5 \mathrm{kPa})$, although their end tidal $\mathrm{PCO}_{2}$ while breathing the gases were much the same. Results from these children (cases 20 and 21) appear at the bottom of tables $1-3$ and are shown by open circles in the figures that follow. In the other 19 children the arterial and end tidal carbon dioxide tensions agreed closely - that is, to within $4 \mathrm{~mm} \mathrm{Hg}$ $(0.5 \mathrm{kPa})$-and the values obtained breathing oxygen were similar to those obtained breathing air so that mean metabolic carbon dioxide production in oxygen was $100.6 \%$ (SD $5.2 \%$ ) of that in air.

Figure 2 shows graphs of the ratios of mean pulmonary arterial pressure, total pulmonary flow, and pulmonary vascular resistance in air and oxygen, plotted against the patients' mean pulmonary artery pressure breathing air. The graphs show that, in these children, pulmonary arterial pressure remained constant or rose on the administration of oxygen (fig $2 a$ ). Total blood flow, however, showed a considerable rise (fig $2 b$ ) and vascular resistance a clear and substantial fall (fig $2 c$ ) in almost all patients.

Details of the data presented in figure 2 are listed in tables 2-4 together with predictions of oxygen consumption, based on the data of Lee and Iliffe. ${ }^{8}$ Inspection of the tables and figures permits the fol- lowing conclusions: (1) the children appeared to be in the same metabolic state when breathing air and when breathing oxygen; (2) the agreement between $\mathbb{\Omega}$ predicted and measured oxygen uptake in these $\overrightarrow{\vec{O}}$ children was poor and the observed oxygen uptake $\frac{}{3}$ varied widely between individuals; (3) administration of oxygen caused an appreciable fall in pulmo-o nary vascular resistance in 16 of the 21 children studied; (4) this fall would not have been detectedo by measurement of pulmonary vascular pressures alone as it was masked by a corresponding rise ino blood flow; and (5) one child with a normal pulmonary artery pressure and the four oldest childreno (aged 8-11 years) with very high pulmonary arterial pressures did not show a rise in blood flow or a fall ing pulmonary vascular resistance.

Table 4 Effect of breathing oxygen on indices of respiration and blood flow expressed as ratio of mean value while breathing oxygen to mean value while breathing air

\begin{tabular}{|c|c|c|c|}
\hline \multirow[t]{2}{*}{ Index } & \multirow{2}{*}{ Ratio } & \multirow{2}{*}{$\frac{\text { mean value breathing } \mathrm{O}_{2}}{\text { mean value breathing air }}(S D)$} & \multirow[t]{2}{*}{ No of children } \\
\hline & & & \\
\hline $\begin{array}{l}\dot{\mathrm{V}} \mathrm{CO}_{2} \\
\mathrm{PaCO}_{2} \\
\mathrm{C}(\mathrm{a}-\mathrm{v})_{2} \mathrm{O}_{2} \\
\mathrm{Q} \mathrm{p} \\
\mathrm{qp} / \dot{\mathrm{Q} s} \\
\mathrm{dp} \\
\mathrm{dp} / \dot{\mathrm{Q} p}\end{array}$ & $\begin{array}{l}1.011 \\
1.017 \\
0.665 \\
1.658 \\
1.578 \\
1.000 \\
0.650\end{array}$ & $\begin{array}{l}(0.056) \\
(0.054) \\
(0.167) \\
(0.515) \\
(0.495) \\
(0.143) \\
(0.191)\end{array}$ & $\begin{array}{l}19 \\
19 \\
21 \\
21 \\
14 \\
21 \\
21\end{array}$ \\
\hline
\end{tabular}

Abbreviations as in tables 2 and 3. 


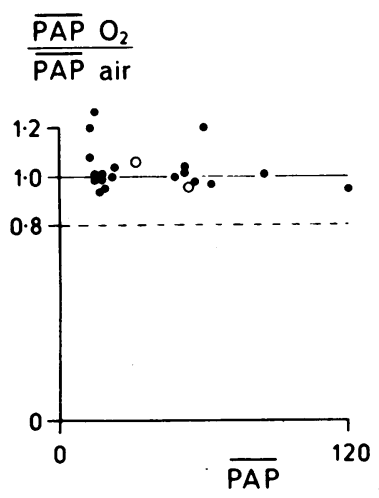

$\boldsymbol{a}$

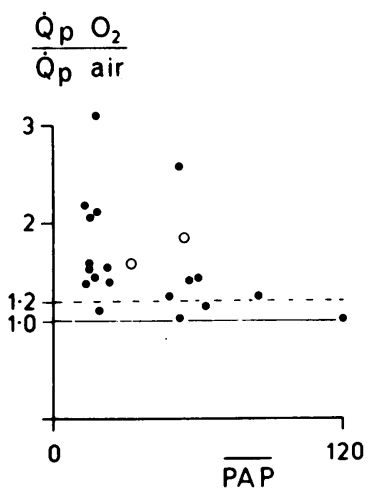

$b$ $\frac{\text { PVR } \mathrm{O}_{2}}{\text { PVR air }}$

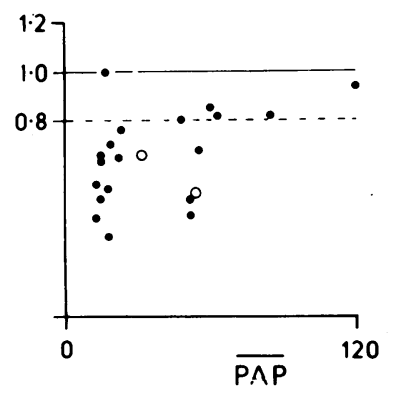

( $\mathrm{mm} \mathrm{Hg}$, breathing air)

Fig 2 Effects of breathing oxygen on: (a) mean pulmonary arterial pressure ( $\overline{P A P})$; (b) total right to left blood flow ( $\dot{Q}$ ); (c) pulmonary vascular resistance (PVR) calculated from $\dot{Q}$. All are expressed as ratios of values seen in oxygen and air, plotted against $\overline{P A P}$. Open circles represent patients 20 and 21 in whom systemic arterial carbon dioxide tensions breathing air and oxygen differed by more than $4 \mathrm{~mm} \mathrm{Hg}(0.5 \mathrm{kPa})$. A $20 \%$ change in the ordinate is represented by a broken line.

\section{Discussion}

The comparison of measured and predicted oxygen consumption (table 2) underlines the findings of others that it may be unwise to predict metabolic gas exchange from published data in children, particularly when they are sedated or anaesthetised. ${ }^{39-11}$ It is much easier to maintain a steady respiratory state in patients who are mechanically ventilated under general anaesthesia, and it seems reasonable to assume that oxygen consumption remained constant during this time as carbon dioxide output and end tidal carbon dioxide were little altered. The maintenance of a fairly constant alveolar partial pressure of oxygen may be important in patients in whom an accurate comparison of haemodynamics is essential.

Classical methods for the direct measurement of respiratory gas exchange are cumbersome and therefore difficult to use during cardiac catheterisation. In the present study the use of long sampling probes and remote mass spectrometry allowed respired and mixed expired gas tensions to be monitored continuously with ease, and metabolic gas exchange to be determined at will, with little or no interference with normal catheterisation routines. If mass spectrometry is used during anaesthesia nitrous oxide should not be used as it has the same mass as carbon dioxide. Automatic methods for distinguishing the two gases are available but, at best, correct for the presence of a gas that can often be avoided. Similarly, it is quite practicable to measure oxygen consumption directly rather than from carbon dioxide production in atmospheres as rich as $90 \%$ oxygen providing $5 \%$ or more of inert gas is included in the inspirate. Although instruments exist for the direct measurement of blood gas contents, they are not particularly suitable for studies such as the one described in which many blood samples are taken over a short time. Instruments that measure blood gas tensions are quicker and simpler to use and reduce delays between sampling and analysis that can be an important source of error.

In the few arterial samples (taken while breathing $100 \%$ oxygen) that had to be kept as long as 20 minutes between drawing and analysis, some diffusion of oxygen through the syringe wall would have occurred. The mean fall in $\mathrm{PO}_{2}$ over 20 minutes in the samples equilibrated in vitro with $100 \%$ oxygen was $54 \mathrm{~mm} \mathrm{Hg}(7.2 \mathrm{kPa})$, representing a fall in oxygen content of $0.15 \mathrm{ml} / 100 \mathrm{ml}$. Such an error in every arterial sample would lead to an overestimate of the response of the pulmonary vasculature to oxygen. In most of our patients this would have been minor, and only two (case 19, the child with the most severe pulmonary hypertension, and case 20 ) would have shown no fall in pulmonary vascular resistance.

Our observations show that almost all patients showed a considerable rise in the oxygen tension of pulmonary arterial blood when oxygen was breathed, while carbon dioxide excretion (and by assumption oxygen uptake) was unaltered. This implies a large increase in total pulmonary blood flow, which could simply reflect a rise in systemic cardiac output or greater intracardiac left to right shunting, or both. In the 14 children in whom superior vena caval blood was sampled the relative contributions of these mechanisms were calculated 

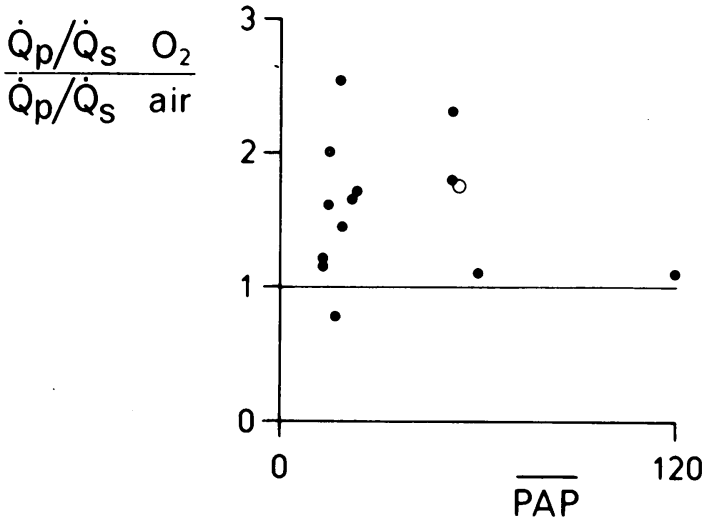

Fig 3 Effects of breathing oxygen on the ratio of total pulmonary flow $(\dot{Q} p)$ to systemic venous return $(\dot{Q} s)$ calculated from the composition of superior vena caval blood in 14 of the 21 children studied. Results are expressed as in fig 2. Open circles represents (1) patient in whom systemic arterial carbon dioxide tensions breathing air and oxygen differed by more than $4 \mathrm{~mm} \mathrm{Hg}(0.5 \mathrm{kPa}) . \overline{P A P}$ represents mean pulmonary arterial pressure.

with the caval $\mathrm{PO}_{2}$ as an admittedly imperfect index of the oxygen tension in systemic venous blood.

Figure 3 shows the results, presented as the ratio of total pulmonary flow (Q́p) to systemic return (Q்) under the two conditions (oxygen and air). It suggests that an increase in intracardiac left to right flow was an important contributor to the greater pulmonary blood flow while breathing oxygen in 10 of the 14 patients. This is a common finding in patients with congenital heart disease. An increase in pulmonary flow, however, has also been noted, in the absence of a shunt, in adults with primary pulmonary hypertension studied in the same manner in these laboratories. ${ }^{12}$ In these subjects the vasodilatation was induced by the intravenous administration of diazoxide. We have also seen the same phenomenon in patients with pulmonary hypertension secondary to chronic obstructive airway disease, after they have been given pirbuterol. ${ }^{13}$

If the ideal alveolar air equation is applied to the data in table 2 it becomes apparent that oxygen administration was accompanied by an appreciable widening of the alveolar-arterial $\mathrm{PO}_{2}$ gradient, often by much more than would have been predicted from the shape of the oxygen-haemoglobin dissociation curve alone. This could be due to a real increase in intracardiac right to left shunt or to less perfect equilibration in the lung. We think that the second is the more likely explanation and that the alveolararterial $\mathrm{PO}_{2}$ gradient widens because the pulmonary vasodilatation is not uniform and in some zones very high pulmonary blood flow may not allow sufficient time for the transfer of oxygen to be completed. For 7 this reason we have presented our results on the assumption that the total pulmonary flow passed through the lung capillaries. Our results show that blood flow must be measured as well as pressure if one wishes to determine the reversibility of a raised pulmonary vascular resistance as a fall in resistance may be manifest solely by a rise in blood flow.

We thank the Research and Development Branch of $\frac{\overrightarrow{\vec{x}}}{x}$ the Department of Health and Social Security and the Clinical Research Committee of the National Heart and Chest Hospitals for generous support.

\section{References}

1 Harris $\mathrm{P}$, Heath D. The human pulmonary circulation. Edinburgh: Churchill Livingstone, 1977:118-36.

2 Widimsky J, Kasalicky J, Valach A, Dejdar R, Vyslonzil Z, Lukes M. Effects of Priscol on the pulmonary circulation in cor pulmonale. $\mathrm{Br} J$ Dis Chest 1.960;22:571.

3 Kappagoda CT, Greenwood P, Macartney FJ, Linden RJ. Oxygen consumption in children with congenital diseases of the heart. Clin Sci Mol Med 1973;45:10714.

4 Davies NJH, Denison DM. The measurement of metabolic gas exchange by mass spectrometry alone. Respir Physiol 1979;36:261-7.

5 Davies NJH, Denison DM. The uses of long sampling probes in respiratory mass spectometry. Respir Physiol 1979;37:335-46.

6 Kelman GR. Digital computer subroutine for the conversion of oxygen tension into oxygen saturation. $J$ Appl Physiol 1966;21:1375-6.

7 Fick A. Ueber die Messung des Blutquantums in der herzventrikein. Verh Phys Med Ges Wurzb 1870;2:169-70.

8 Lee VA, Iliffe A. The energy metabolism of infants and young children during post-prandial sleep. Pediatrics 1956; 18:739-49.

9 Baum D, Brown AC, Church SC. Effect of sedation on oxygen consumption of children undergoing cardiac catheterisation. Pediatrics 1967;39:891-5.

10 Owen-Thomas JB, Meade F, Jones RS, Jackson-Rees $D$ G. The measurement of oxygen uptake in infants with congenital diseases of the heart. Clin Sci Mol Med 1971;45:107-14.

11 Fixler DE, Carrell T, Browne R, Willis K, Miller WW. Oxygen consumption in children during cardiac catheterisation under different sedation regimes. Circulation 1974;50: 788-94.

12 Honey M, Cotter L, Davies N, Denison D. The clinical and haemodynamic effects of diazoxide in primary pulmonary hypertension. Thorax 1980;35:269-76.

13 Peacock AJ, Busst C, Denison DM. Response of the pulmonary circulation to oral pirbuterol in patients with chronic airflow obstruction. $\mathrm{Br}$ Med J 1983;287: 1178-80. 